\title{
THE BALLISTOCARDIOGRAM IN MITRAL VALVULAR DISEASE
}

\author{
BY \\ G. IZAK AND K. BRAUN* \\ From the Cardiovascular Laboratory and Internal Medical Department, Division B, \\ Rothschild Hadassah University Hospital, Jerusalem
}

Received January 3, 1955

In 1940 Starr reported several cases of rheumatic heart disease in which the ballistocardiogram showed an abnormal pattern; clinical improvement was associated with return of the pattern toward normal. Following this report, several authors found the ballistocardiogram abnormal in a high percentage of cases of rheumatic valvular disease. The changes noted were small I waves, notching and slurring of the I-J segments, tall $\mathrm{L}$ and $\mathrm{N}$ waves, and " bowing" of $\mathrm{J}-\mathrm{K}$ segments. However, these changes were not considered as pathognomonic of specific types of valvular lesion. The first attempt to ascribe these changes to a specific valvular lesion was by Davis et al. (1953) who found in cases of " pure" mitral stenosis an additional wave preceding the normal I wave. They referred to this abnormality as " doubling" of the I wave. Dock et al. (1953) noted several characteristic alterations in the ballistocardiogram in cases of pure mitral stenosis. These included lack of respiratory variation of the $J$ waves and an absence of increase of the $J$ waves following exercise. Brown et al. (1952) observed tall $\mathrm{N}$ waves in several cases of mitral stenosis. In cases of mitral insufficiency, Kuo and Schnabel (1953) described an additional positive systolic deflection interposed between the I and $\mathbf{J}$ waves.

This study was undertaken to determine if characteristic changes in the ballistocardiogram do occur in cases of mitral stenosis and/or insufficiency. Furthermore, serial records were studied in a number of patients with mitral stenosis both before and after mitral valvotomy.

\section{MATERIAL AND Methods}

The records were obtained from a high-frequency ballistocardiograph (Sanborn) following a four-hour fasting period, late in the morning.

Forty-four patients are included in this study, all of whom suffered from rheumatic mitral valvular disease, presumably inactive. The diagnosis was established according to the usual clinical, X-ray, electrocardiographic, and other laboratory data. In 31 of the 44 patients, cardiac catheterization was performed. In the patients who underwent valvotomy, serial ballistocardiograms were recorded before operation and during a period of from two months to one year following valvotomy.

The first group comprises 30 patients with predominant mitral stenosis (Table I) of whom 20 had successful valvotomy carried out by Mr. H. Milwidsky ; in two of them, a mild degree of insufficiency was detected at the time of valvotomy. In four others valvotomy was not attempted because extensive thrombosis in the left atrium was found at the time of operation. Of the six unoperated cases, there was no significant degree of incapacity in three and three were in advanced congestive heart failure.

The second group consists of fourteen patients with predominant mitral insufficiency With three exceptions (aged 16, 17, and 43 years) all were in the age group 20-40 years. All had some degree of incapacity, severe in 7 (4 with signs of congestive heart failure).

The ballistocardiograms were examined with regard to amplitude, shape, and time relations between the ballistic waves and the QRS complexes of the electrocardiogram and the intervals between the various ballistic waves were measured. An attempt was made to correlate the hæmodynamic data obtained by

* This study was carried out with the support of the Lown Fund. 
cardiac catheterization with the various ballistic waves, such as (1) left and right atrial pressures to the G-H, M-N complexes; (2) pulmonary artery pressure, pulmonary vascular resistance, and right ventricular work on one hand, to the H-I-J complexes on the other hand; (3) cardiac output to the J waves; and (4) systemic vascular resistance and peripheral arterial pressures to the $\mathbf{J}-\mathrm{K}$ complexes.

TABLE I

Clinical Features of Cases of Mitral Stenosis

\begin{tabular}{|c|c|c|c|c|c|c|}
\hline $\begin{array}{c}\text { Patient } \\
\text { No. }\end{array}$ & Age & Sex & $\begin{array}{l}\text { Degree of } \\
\text { incapacity }\end{array}$ & \multicolumn{2}{|c|}{$\begin{array}{l}\text { Congestive heart failure: } \\
\text { Before After } \\
\quad \text { valvotomy }\end{array}$} & Diagnosis \\
\hline $\begin{array}{r}1 \\
2 \\
3 \\
4 \\
5 \\
6 \\
7 \\
8 \\
9 \\
10 \\
11 \\
12 \\
13 \\
14 \\
15 \\
16 \\
17 \\
18 \\
19 \\
20 \\
21 \\
22 \\
23 \\
24 \\
25 \\
26 \\
27 \\
28 \\
29 \\
30\end{array}$ & $\begin{array}{l}29 \\
27 \\
44 \\
22 \\
31 \\
21 \\
38 \\
22 \\
23 \\
23 \\
31 \\
40 \\
30 \\
32 \\
19 \\
31 \\
19 \\
22 \\
33 \\
17 \\
42 \\
47 \\
22 \\
40 \\
19 \\
25 \\
16 \\
45 \\
26 \\
44\end{array}$ & $\begin{array}{l}F \\
M \\
F \\
F \\
M \\
F \\
F \\
F \\
F \\
F \\
F \\
F \\
M \\
F \\
M \\
F \\
M \\
M \\
F \\
F \\
M \\
F \\
M \\
F \\
F \\
F \\
F \\
F \\
F \\
F\end{array}$ & $\begin{array}{l}+++ \\
++ \\
+++ \\
++ \\
++ \\
++ \\
++ \\
++ \\
++ \\
++ \\
++ \\
+++ \\
++ \\
+++ \\
++ \\
++ \\
+++ \\
++ \\
++ \\
++ \\
++ \\
++ \\
+ \\
+++ \\
+ \\
+ \\
+ \\
+++ \\
++ \\
+++\end{array}$ & $\begin{array}{l}+ \\
+ \\
++ \\
0 \\
+ \\
+ \\
+ \\
0 \\
+ \\
+ \\
+ \\
+++ \\
0 \\
++ \\
0 \\
+ \\
++ \\
0 \\
+ \\
0 \\
0 \\
0 \\
0 \\
++ \\
0 \\
0 \\
0 \\
+ \\
+ \\
++\end{array}$ & $\begin{array}{c}+ \\
0 \\
0 \\
0 \\
0 \\
0 \\
+ \\
0 \\
0 \\
0 \\
0 \\
0 \\
0 \\
0 \\
0 \\
0 \\
0 \\
0 \\
+ \\
0 \\
\text { No valvotomy } \\
\text { No valvotomy } \\
\text { No valvotomy } \\
\text { No valvotomy } \\
\text { No operation } \\
\text { No operation } \\
\text { No operation } \\
\text { No operation } \\
\text { No operation } \\
\text { No operation }\end{array}$ & $\begin{array}{c}\text { Stenosis } \\
\text { Stenosis } \\
\text { Stenosis } \\
\text { Stenosis } \\
\text { Stenosis } \\
\text { Stenosis } \\
\text { Stenosis } \\
\text { Stenosis } \\
\text { Stenosis } \\
\text { Stenosis } \\
\text { Stenosis } \\
\text { Stenosis } \\
\text { Stenosis } \\
\text { Stenosis } \\
\text { Stenosis } \\
\text { Stenosis } \\
\text { Stenosis } \\
\text { Stenosis } \\
\text { Sten. and Ins. } \\
\text { Sten. and Ins. } \\
\text { Stenosis } \\
\text { Stenosis } \\
\text { Stenosis } \\
\text { Stenosis } \\
\text { Stenosis } \\
\text { Stenosis } \\
\text { Stenosis } \\
\text { Stenosis } \\
\text { Stenosis } \\
\text { Stenosis }\end{array}$ \\
\hline
\end{tabular}

\section{RESULTS}

Time Relations between Ballisto- and Electrocardiographic Deflections. The time intervals between the $\mathrm{Q}$ waves and the I waves of the ballistocardiogram were found to be fairly constant, regardless of whether stenosis or insufficiency was present, and varied from $0 \cdot 15$ to 0.17 second. The time intervals between the $I$ and $K$ waves were also fairly constant and varied from $0 \cdot 14$ to 0.18 second. These slight variations in the intervals were apparently due to the differences in the pulse rate.

Correlation between the Hamodynamics of the Right Heart and the H-I Complexes. Of 30 patients with mitral stenosis, comprising the first group, cardiac catheterization was performed in 27: in 16 of these pulmonary artery pressure and pulmonary vascular resistance were found to be much increased, more than $60 / 30 \mathrm{~mm}$. $\mathrm{Hg}$ and $600 \mathrm{dyn} . / \mathrm{cm} .{ }^{-5} / \mathrm{sec}$. respectively. In 10 out of these 16 cases the $H$ waves were much enlarged and in most of them peaked. In the remaining 6 the $\mathrm{H}$ waves were slurred and small or iso-electric. In the 11 in which the pulmonary artery pressure and the pulmonary vascular resistance were normal or moderately raised (up to $50 / 20 \mathrm{~mm}$. $\mathrm{Hg}$ and $400 \mathrm{dyn} . / \mathrm{cm} .-5 / \mathrm{sec}$. respectively), the $\mathrm{H}$ waves appeared normal in nine and enlarged in one. Ballistocardiograms after operation showed a gradual change of the enlarged $\mathrm{H}$ waves toward normal. 
In 4 of the 14 patients suffering from predominant mitral insufficiency, the pulmonary artery pressures and pulmonary vascular resistances were measured and were found to be raised in three. In two of the latter the $\mathrm{H}$ waves were enlarged while in the other two they were normal.

Cardiac Output and $J$ Waves. Cardiac output was calculated according to the Fick principle in 31 cases. No correlation was found between the cardiac output and the size of the $\mathbf{J}$ waves. In most cases the $J$ waves were small but of normal shape prior to operation. In cases where the $\mathbf{J}$ waves were small, a significant increase of the I-J stroke was observed after successful valvotomy.

Peripheral Arterial Pressure, Systemic Vascular Resistance, and $K$ Waves. The $\mathrm{K}$ waves of the ballistocardiogram tended to be deep in most of the cases, regardless of the height of the peripheral arterial pressure and systemic vascular resistance, and did not change significantly after valvotomy.

$L, M, N$ Waves. Tall $\mathrm{N}$ waves were found in three of the twelve cases with pure mitral stenosis without congestive heart failure. Of the ten cases with predominant mitral insufficiency without congestive heart failure, one showed tall $\mathrm{N}$ waves. Tall $\mathrm{L}$ and $\mathrm{N}$ waves were found in 16 out of the 22 patients with congestive heart failure, whether the underlying condition was predominant mitral stenosis or insufficiency.

General Appearance of the Ballistocardiogram. There was a good correlation between the clinical picture (subjective complaints, degree of incapacity, right-heart enlargement, degree of pulmonary congestion, etc.) and the pattern of the ballistocardiogram. Prior to valvotomy the ballistic pattern was irregular, the respiratory variations were marked, and the interrelation of the various waves disproportional. Following valvotomy the $J$ waves appeared abnormal and were slurred or notched for a period of about three months; thereafter where the clinical and laboratory data suggested improvement a gradual return of the ballistic pattern to normal occurred. This change in the ballistic pattern was especially evident with regard to the H-I-J-K complexes. Table II summarizes the results obtained by cardiac catheterization in 17 of the 18 patients who underwent valvotomy; Fig. 1 shows a schematic drawing of the ballistocardiograms before and after valvotomy. Fig. 2 illustrates serial records obtained in Case 3 before and after valvotomy.

\section{DisCUSSION}

This study was undertaken to evaluate the aid offered by the ballistocardiogram in the differential diagnosis between predominant mitral stenosis and predominant mitral insufficiency, and in the

TABLE II

Hemodynamic Data in 17 Patients with Mitral Stenosis who underwent Valvotomy

\begin{tabular}{|c|c|c|c|c|c|c|}
\hline $\begin{array}{l}\text { Patient } \\
\text { No. }\end{array}$ & $\begin{array}{l}\text { Pulmonary } \\
\text { artery } \\
\text { pressure } \\
(\mathrm{mm} . \mathrm{Hg})\end{array}$ & $\begin{array}{c}\text { Pulmonary } \\
\text { vascular } \\
\text { resistance } \\
\text { (dyn. } / \mathrm{cm} .^{-5} / \mathrm{sec} \text { ) }\end{array}$ & $\begin{array}{c}\text { Systemic } \\
\text { arterial } \\
\text { pressure } \\
(\mathrm{mm} . \mathrm{Hg})\end{array}$ & $\begin{array}{c}\text { Systemic } \\
\text { vascular } \\
\text { resistance } \\
\text { (dyn./cm. }-5 / \mathrm{sec} \text {.) }\end{array}$ & $\begin{array}{l}\text { Cardiac } \\
\text { oıtput } \\
\text { (l./min.) }\end{array}$ & $\begin{array}{l}\text { R.V. work } \\
\text { (kg./min.) }\end{array}$ \\
\hline $\begin{array}{r}1 \\
2 \\
3 \\
4 \\
5 \\
6 \\
7 \\
10 \\
11 \\
13 \\
14 \\
15 \\
16 \\
17 \\
18\end{array}$ & $\begin{array}{c}24 / 9 \\
32 / 13 \\
75 / 40 \\
98 / \\
\text { No catheteri } \\
42 / 15 \\
76 / 13 \\
70 / 50 \\
50 / 35 \\
42 / 23 \\
102 / 48 \\
83 / 39 \\
62 / 27 \\
121 / 50 \\
88 / 45\end{array}$ & $\begin{array}{c}261 \\
267 \\
1001 \\
1273 \\
\text { ation performed } \\
593 \\
1146 \\
1850 \\
405 \\
688 \\
1475 \\
815 \\
790 \\
2005 \\
1009\end{array}$ & $\begin{array}{r}100 / 85 \\
120 / 90 \\
105 / 75 \\
110 / 70 \\
100 / 75 \\
120 / 85 \\
85 / 65 \\
90 / 70 \\
105 / 80 \\
103 / 61 \\
115 / 70 \\
105 / 70 \\
110 / 80 \\
105 / 65\end{array}$ & $\begin{array}{r}1429 \\
1025 \\
1345 \\
2575 \\
1822 \\
2019 \\
2220 \\
940 \\
2021 \\
2360 \\
1028 \\
1720 \\
2360 \\
1555\end{array}$ & $\begin{array}{l}5 \cdot 2 \\
7 \cdot 8 \\
5 \cdot 1 \\
2 \cdot 7 \\
\\
3 \cdot 6 \\
3 \cdot 8 \\
2 \cdot 7 \\
7 \cdot 5 \\
3 \cdot 5 \\
2 \cdot 7 \\
5 \cdot 9 \\
4 \cdot 1 \\
3 \cdot 4 \\
4 \cdot 0\end{array}$ & $\begin{array}{l}1 \cdot 20 \\
1 \cdot 70 \\
3 \cdot 57 \\
1 \cdot 58 \\
0.67 \\
1 \cdot 33 \\
2 \cdot 87 \\
4 \cdot 26 \\
1 \cdot 41 \\
1 \cdot 84 \\
4 \cdot 81 \\
2 \cdot 55 \\
3 \cdot 93 \\
2 \cdot 72\end{array}$ \\
\hline
\end{tabular}

The serial numbers correspond to those in Table I. 

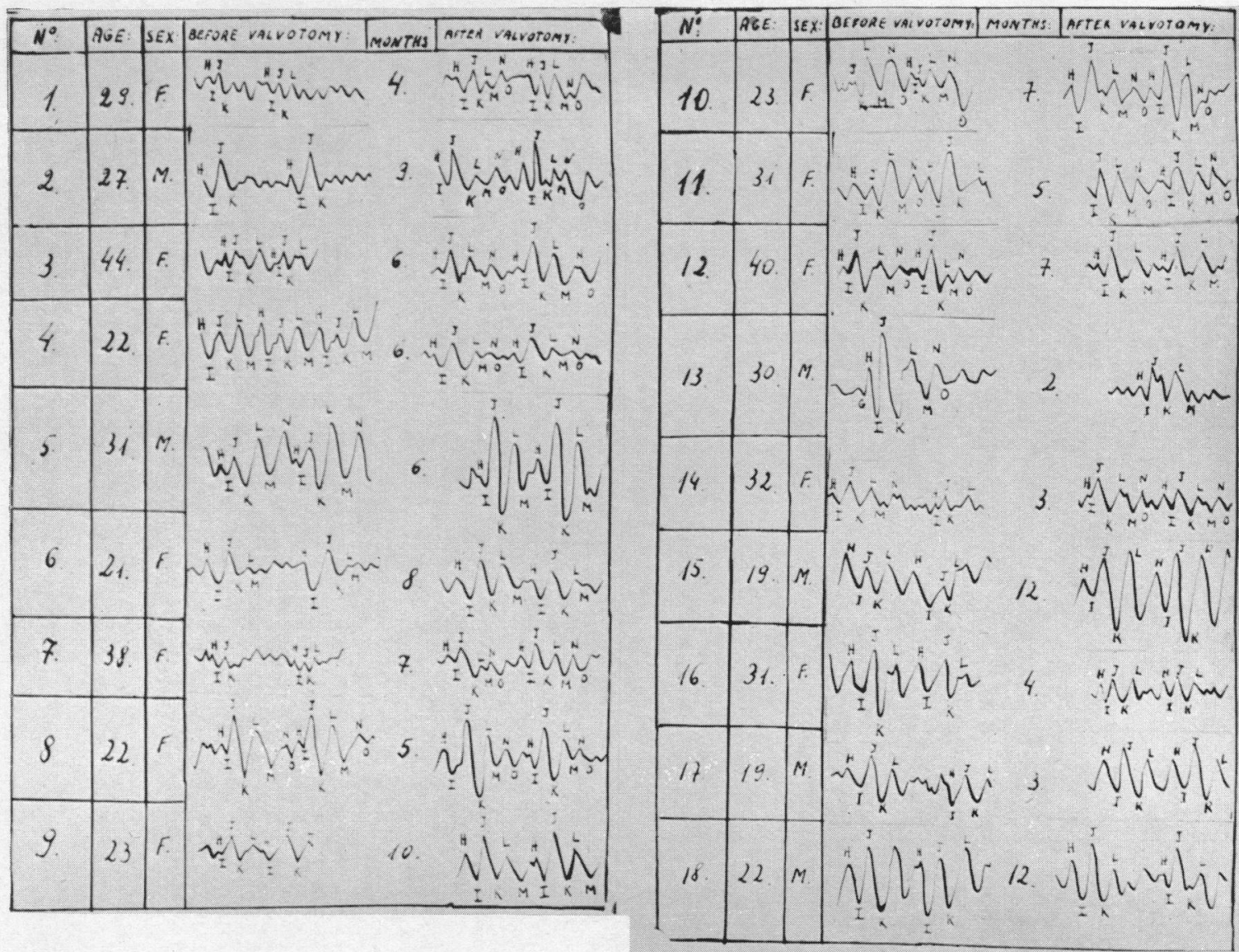

Fig. 1.-Schematic drawings of ballistocardiograms obtained before and after valvotomy. The serial numbers correspond to those in Tables I and II.

evaluation of the hæmodynamic alterations occurring in patients undergoing valvotomy. The reports of Davis et al. (1953) and Kuo et al. (1953) suggest that the ballistic pattern may be of value in differentiating patients with stenosis from those with predominant mitral insufficiency. However, in our series none of the previously described abnormalities such as "doubling" of the I wave, or the interposed upward deflection between I and $\mathrm{J}$ were found to be characteristic for either mitral stenosis or insufficiency. Tall $\mathrm{L}$ and $\mathrm{N}$ waves were found fairly regularly in cases of congestive heart failure, whether due to mitral stenosis or to mitral insufficiency. It appears to us, therefore, that the ballistocardiogram is of no value for differentiating between mitral stenosis and insufficiency. Non-specific changes such as marked respiratory variations, irregular pattern, and small $\mathrm{J}$ waves were present in a high percentage of patients with either mitral stenosis or insufficiency.

Follow-up ballistocardiograms after valvotomy showed return toward normal of the exaggerated respiratory variations and of the irregular pattern present before operation. The notching and slurring of the $\mathbf{J}$ waves found immediately following operation, which probably indicated myocardial damage due to the surgical procedure, disappeared within about three months and the I-J stroke became normal. These observations indicate that the ballistocardiogram may be a reliable method of evaluating hæmodynamic alterations after valvotomy (Reissman et al., 1953).

An attempt was made to correlate the various hæmodynamic data obtained by cardiac catheterization with the various ballistic waves. The small number of cases with extreme pulmonary 


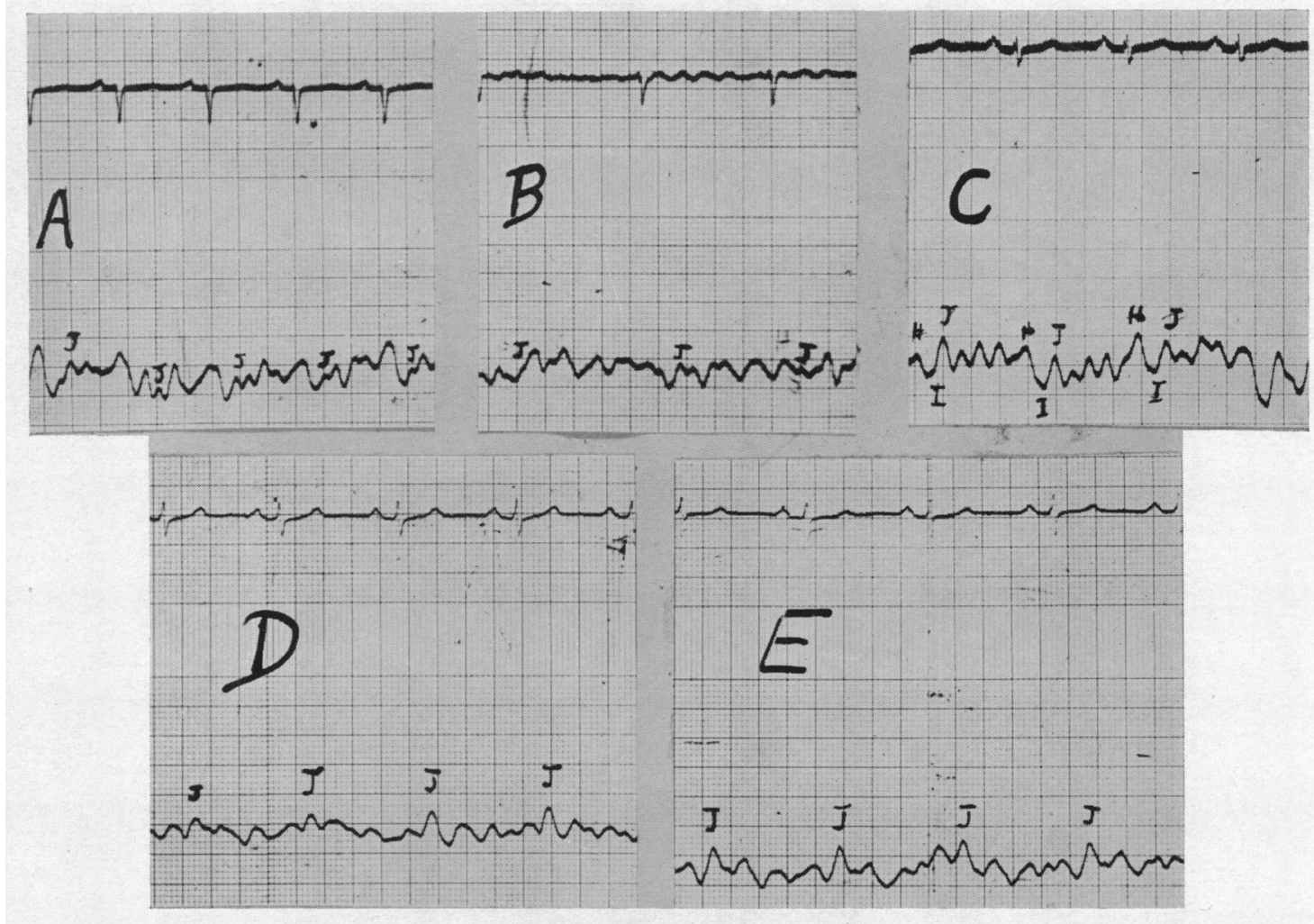

FIG. 2.-Serial ballistocardiographic records from a patient with tight mitral stenosis before (A) and following valvotomy $(B-E)$. The last record $(E)$, was taken five months after operation.

hypertension, in which the $\mathrm{H}-\mathrm{I}$ complexes were much enlarged, are too few to indicate significant correlation. No correlation was found between the cardiac output and the size of the $J$ waves. Neither was there any parallelism between the peripheral blood pressure or peripheral systemic vascular resistance and the size of the $\mathrm{K}$ waves.

\section{SUMMARY}

The ballistocardiogram was recorded in 44 patients with rheumatic valvular disease, mitral stenosis, and mitral insufficiency. In 18 of these, mitral valvotomy was successfully performed and serial ballistocardiograms were recorded at monthly intervals.

The ballistocardiogram did not reveal any specific pattern either for mitral stenosis or for mitral insufficiency.

No correlation could be established between the hæmodynamic data obtained by cardiac catheterization and the changes found in the ballistocardiogram. The ballistocardiogram was, however, thought to be a useful index for evaluating clinical improvement after successful valvotomy.

\section{REFERENCES}

Brown, H. R., de Lalla, V., Epstein, M. A., and Hoffman, M. J. (1952). Clinical Ballistocardiography. New York, p. 161 .

Davis, F. W., Scarborough, W. R., Mason, R. E., Singewald, M. L., and Baker, B. M. (1953). Circulation, 7, 503. Dock, W., Mandelbaum, H., and Mandelbaum, R. A. (1953). Ballistocardiography. C. V. Mosby Comp., p. 205. Kuo, P. T., and Schnabel, T. G. (1953). Amer. J. Med., 15, 50.

Reissmann, R. R., and Dimond, E. G. (1953). Circulation, 8, 585.

Starr, I., and Schroeder, H. A. (1940). J. Clin. Invest., 13, 437. 